Supplement of Atmos. Chem. Phys., 19, 3857-3871, 2019

https://doi.org/10.5194/acp-19-3857-2019-supplement

(c) Author(s) 2019. This work is distributed under

the Creative Commons Attribution 4.0 License.

(c) (1)

Supplement of

\title{
Links of climate variability in Arctic sea ice, Eurasian teleconnection pattern and summer surface ozone pollution in North China
}

Zhicong Yin et al.

Correspondence to: Zhicong Yin (yinzhc@163.com)

The copyright of individual parts of the supplement might differ from the CC BY 4.0 License. 


\section{Supplementary Information}

Table S1. The number of days with MOP and NOP events.

5

\begin{tabular}{ccccccccccccc}
\hline & $\mathbf{2 0 0 7}$ & $\mathbf{2 0 0 8}$ & $\mathbf{2 0 0 9}$ & $\mathbf{2 0 1 0}$ & $\mathbf{2 0 1 1}$ & $\mathbf{2 0 1 2}$ & $\mathbf{2 0 1 3}$ & $\mathbf{2 0 1 4}$ & $\mathbf{2 0 1 5}$ & $\mathbf{2 0 1 6}$ & $\mathbf{2 0 1 7}$ & Mean \\
\hline MOP & 22 & 8 & 8 & 24 & 14 & 9 & 10 & 11 & 26 & 11 & 12 & 14 \\
NOP & 4 & 12 & 12 & 8 & 4 & 17 & 22 & 9 & 4 & 18 & 16 & 11.5 \\
\hline
\end{tabular}

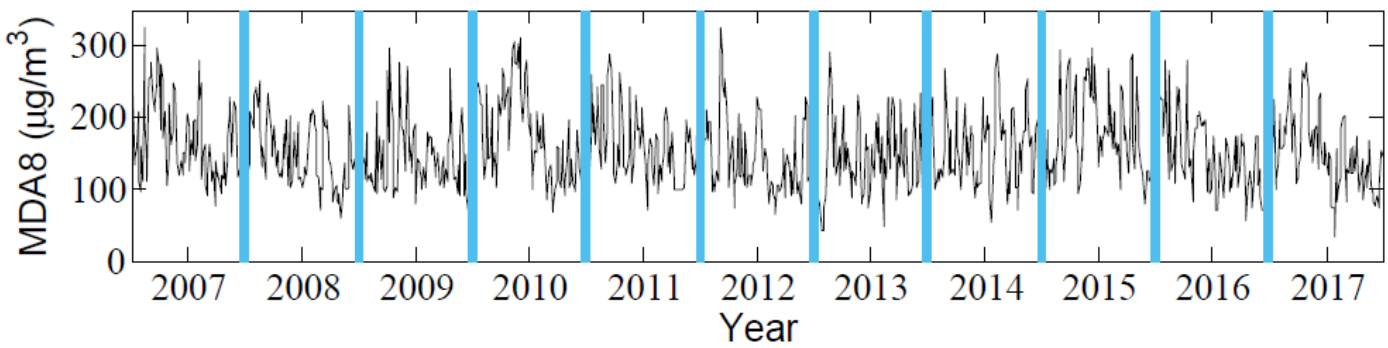

Figure S1. The variation in the SDZ MDA8 from June to August during 2007-2017.The blue lines were used to divide the

data in different years. For example, the data on two sides of the first lines belonged to JJA 2007 and JJA 2008, respectively.
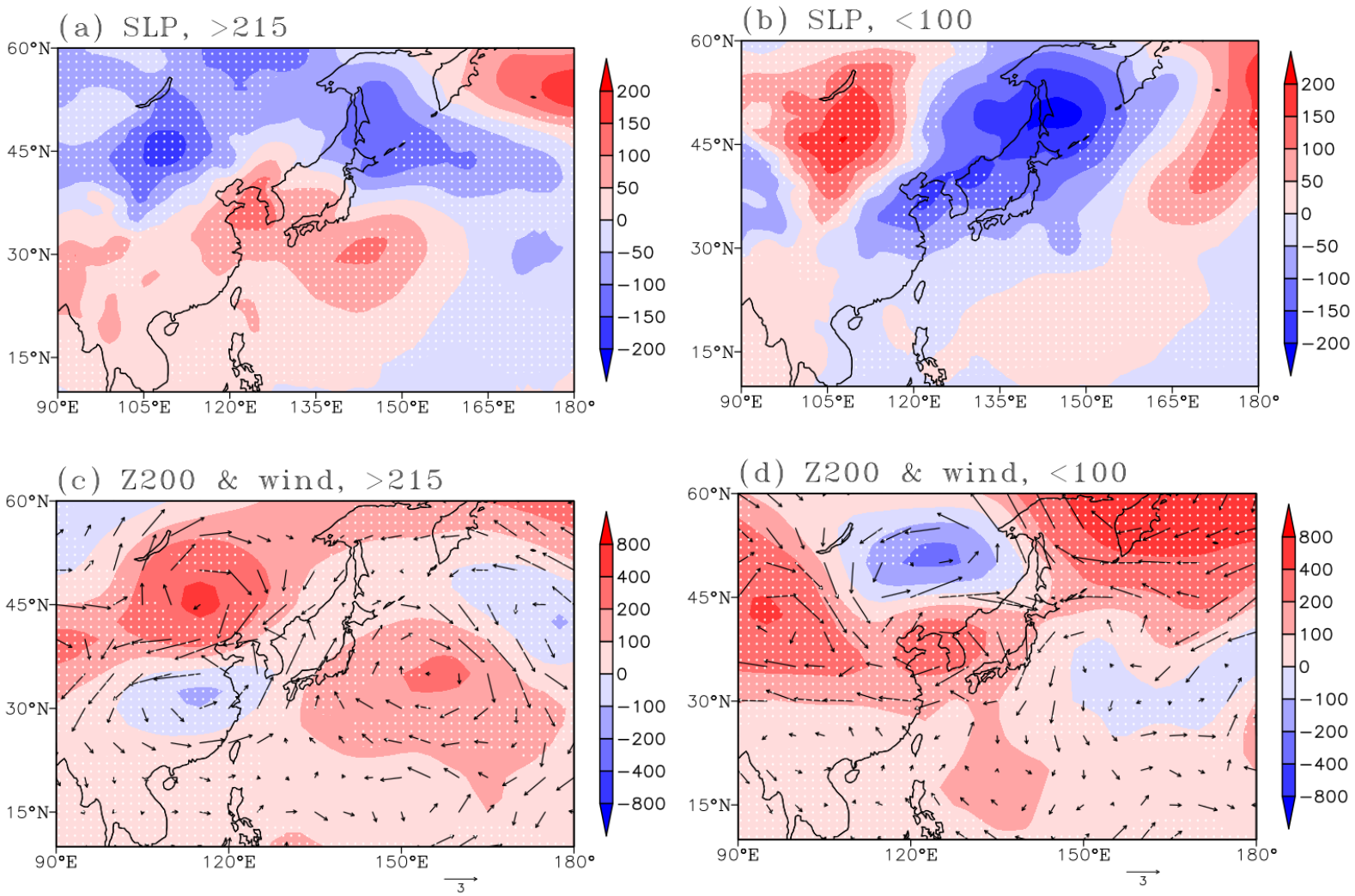

15 Figure S2. Composite of the atmospheric circulations associated with different O3 events during 2007-2017. Results for MOP (a, c) and NOP (b, d) events included ( $a-b)$ sea level pressure (shading), (c-d) geopotential height (shading) and wind (arrow) at $200 \mathrm{hPa}$. The black dots indicate that the composite passed the $95 \%$ confidence level. These composites were calculated using the ERA-Interim datasets. 
(a) Wind \& $v 10 \mathrm{~m} \mathrm{sfc},>215$

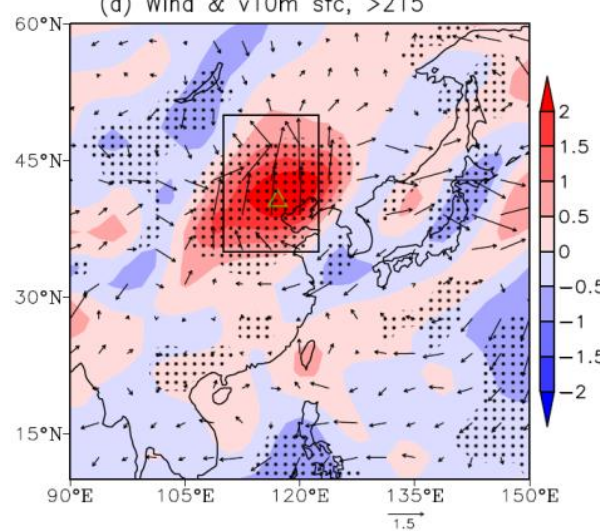

(c) $\mathrm{BLH},>215$

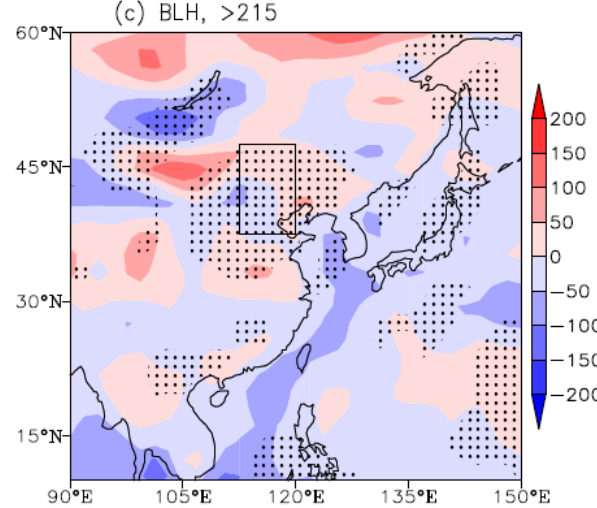

(e) Precipitation, $>215$
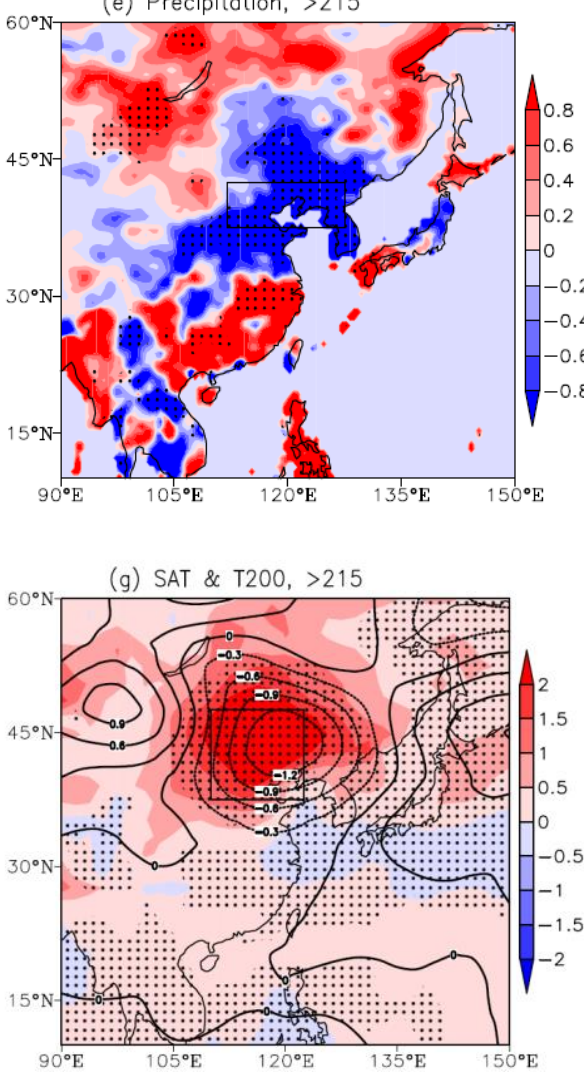

(b) Wind \& v10m sfc, $<100$

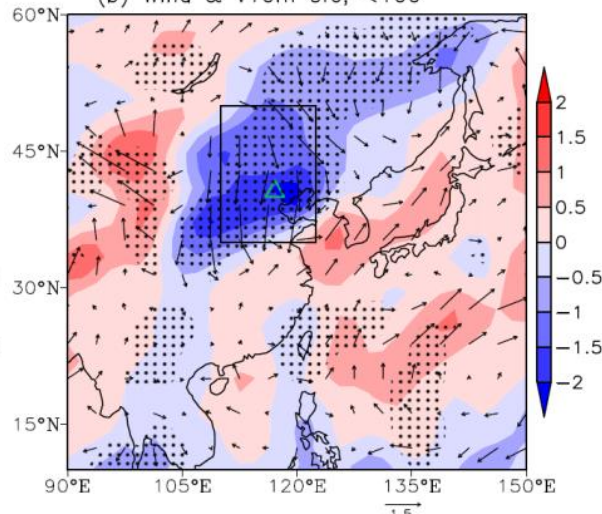

(d) $\mathrm{BLH},<100$

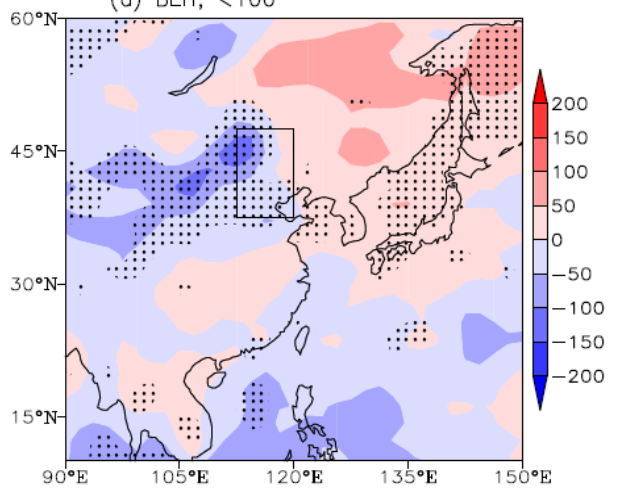

(f) Precipitation, <100

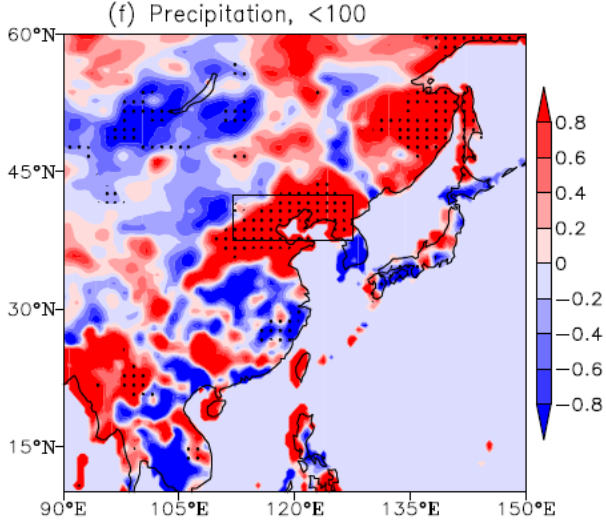

(h) SAT \& T200, <100

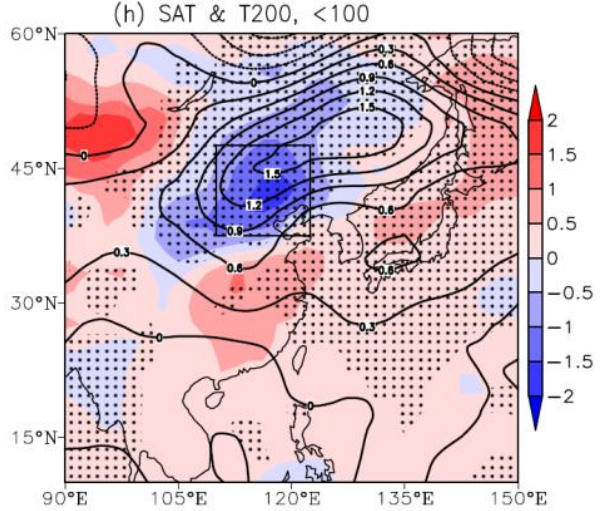

Figure S3. Composite of the meteorological conditions associated with different $\mathrm{O}_{3}$ events during 2007-2017. Results for MOP (a, c, e, g) and NOP (b, d, f, h) events included (a-b) surface wind ( $\mathrm{m} / \mathrm{s}$, arrow) and v-wind (m/s, shading), (c-d) BLH (m), (e-f) precipitation (mm), (g-h) SAT $\left({ }^{\circ} \mathrm{C}\right.$, shading), and temperature at $200 \mathrm{hPa}\left({ }^{\circ} \mathrm{C}\right.$, contour). The black dots denote the composite results passed the $95 \%$ confidence level. The boxes represent the area used to calculate OWI. These composites were calculated using the NCEP/NCAR dataset. The green triangle in panel (a-b) illustrates the location of the Shangdianzi 
site. The composite results were calculated as the differences between MOP or NOP events with the rest events (i.e., all events but excluded MOP and NOP events).
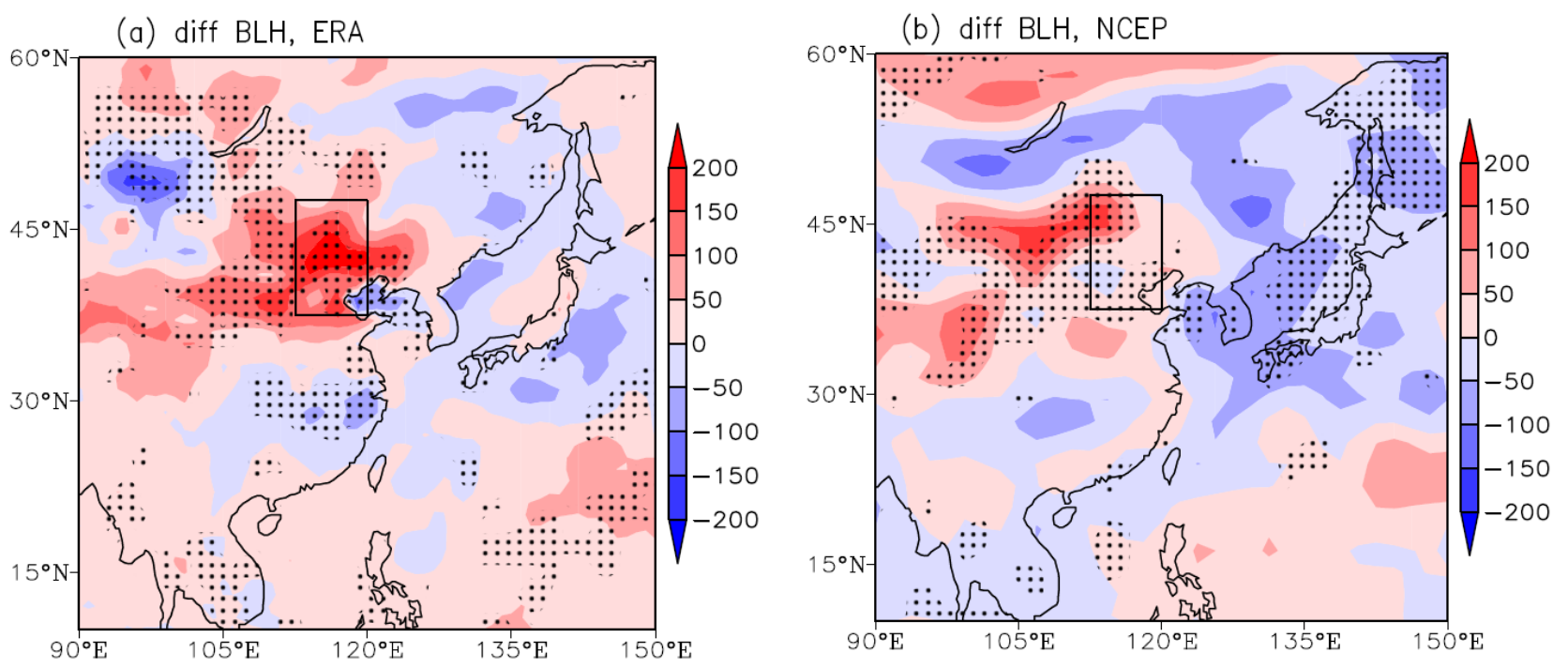

Figure S4. Differences in the boundary layer height between the MOP and NOP events during 2007-2014, based on the ERA-Interim (a) and NCEP/NCAR datasets (b). The black dots denote that the composite passed the $95 \%$ confidence level.

The boxes represent the area to calculate the daily OWI. 
(a) UV200,Z500,SAT | OWI index

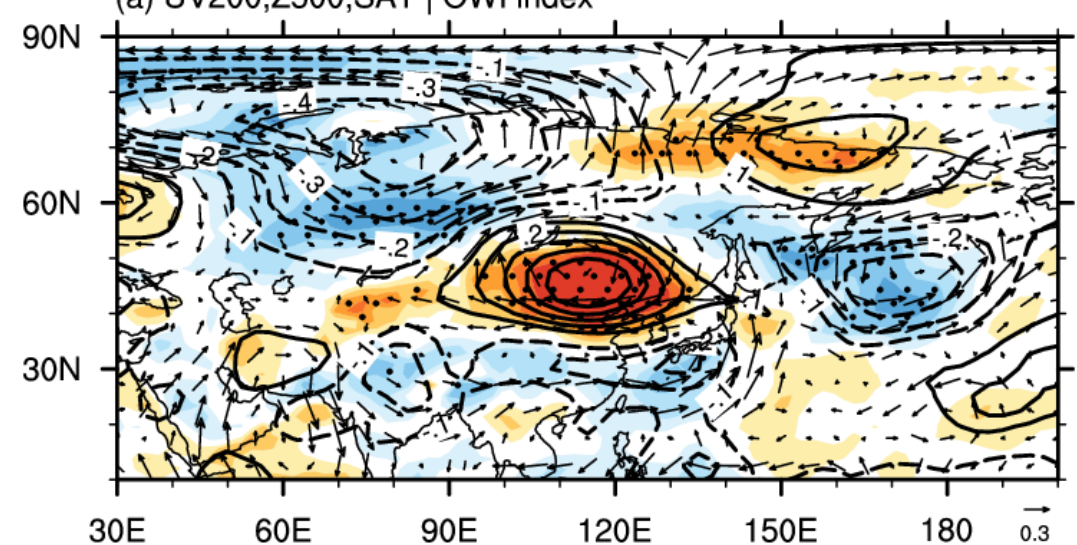

(b) Wind,Rhu,T | OWI index $\overrightarrow{0.3}$

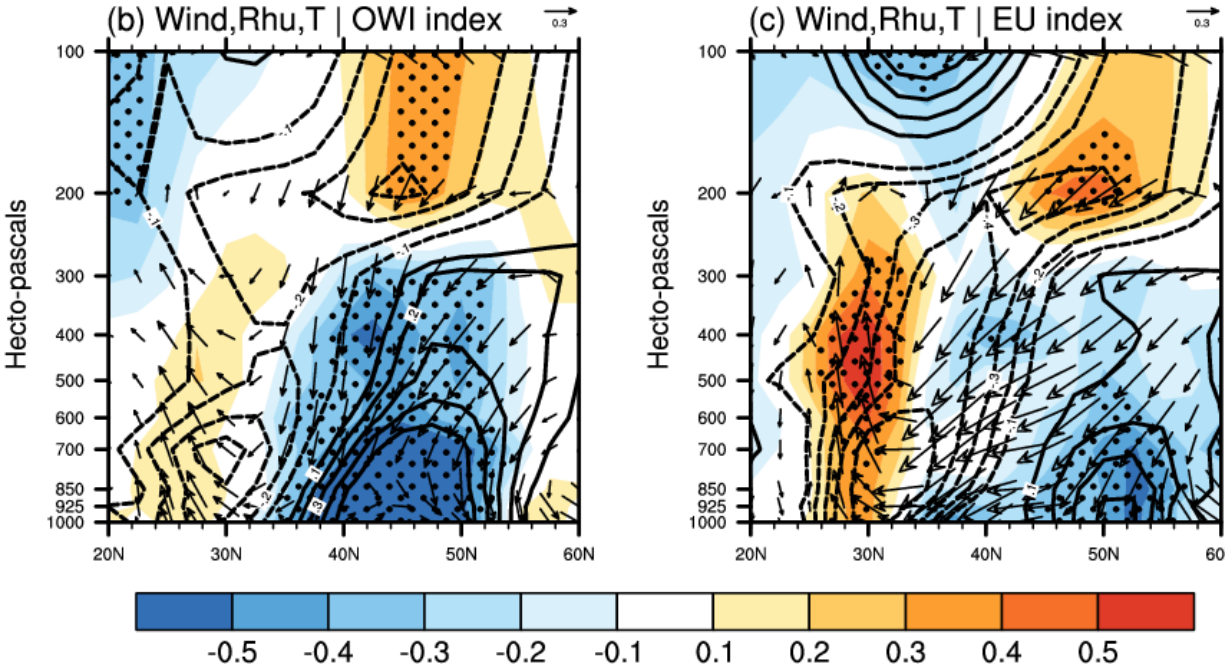

Figure S5. The associated atmospheric circulation. (a) The correlation coefficients between the JJA mean OWI and surface air temperature (shading), wind (arrow) at $200 \mathrm{hPa}$ and geopotential height at $500 \mathrm{hPa}$ (contour) from 1979 to 2017 . The black dots indicate that the $\mathrm{CC}$ with surface air temperature was above the $95 \%$ confidence level. The cross-section $\left(110^{\circ}-\right.$

$125^{\circ} \mathrm{E}$ mean) correlation coefficients between JJA mean OWI (a), EUTP index (b) and relative humidity (shading), temperature (contour), wind (arrow, vertical speed multiplied by 100) from 1979 to 2017. The black dots indicate the CC with relative humidity exceeding the $95 \%$ confidence level ( $\mathrm{t}$ test). The data used here are NCEP/NCAR datasets. 
(a) v10 \& Wind sfc

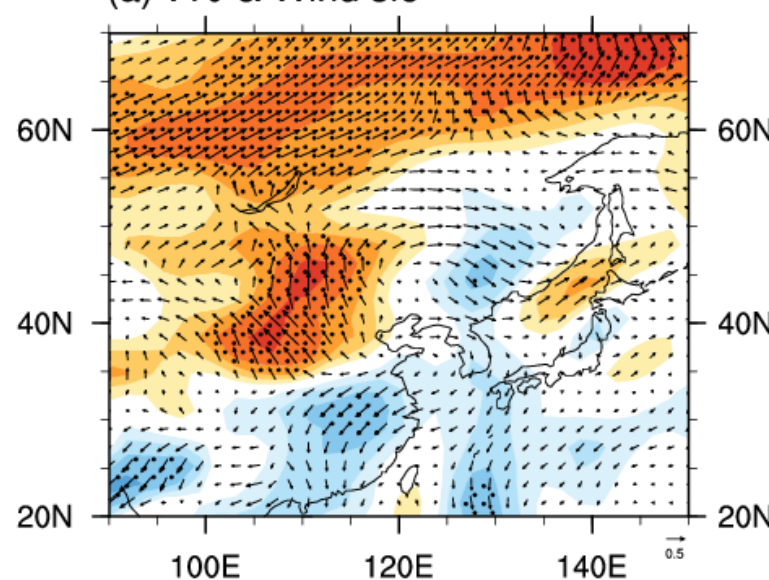

(c) Precipitation \& UVB

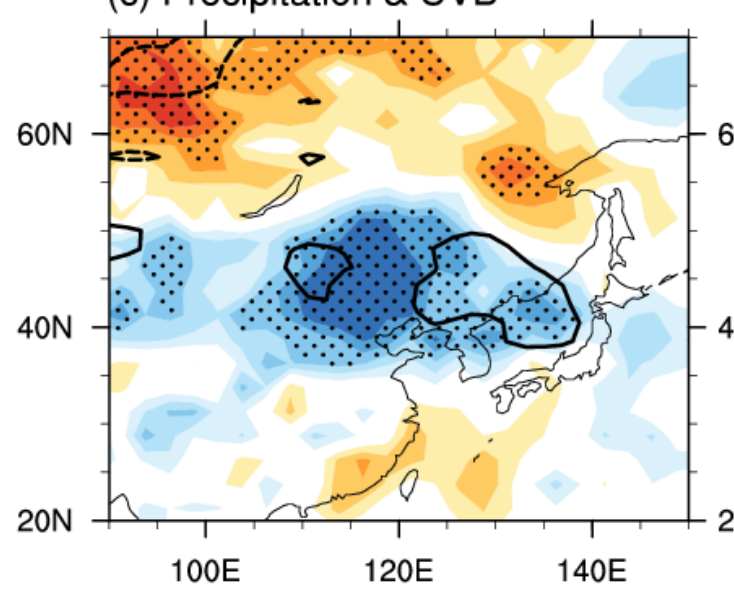

(b) Rhu \& BLH

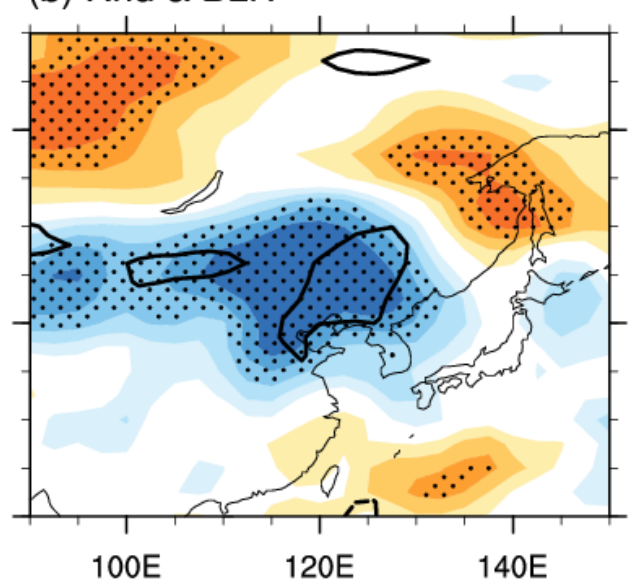

(d) ssrd \& tcc
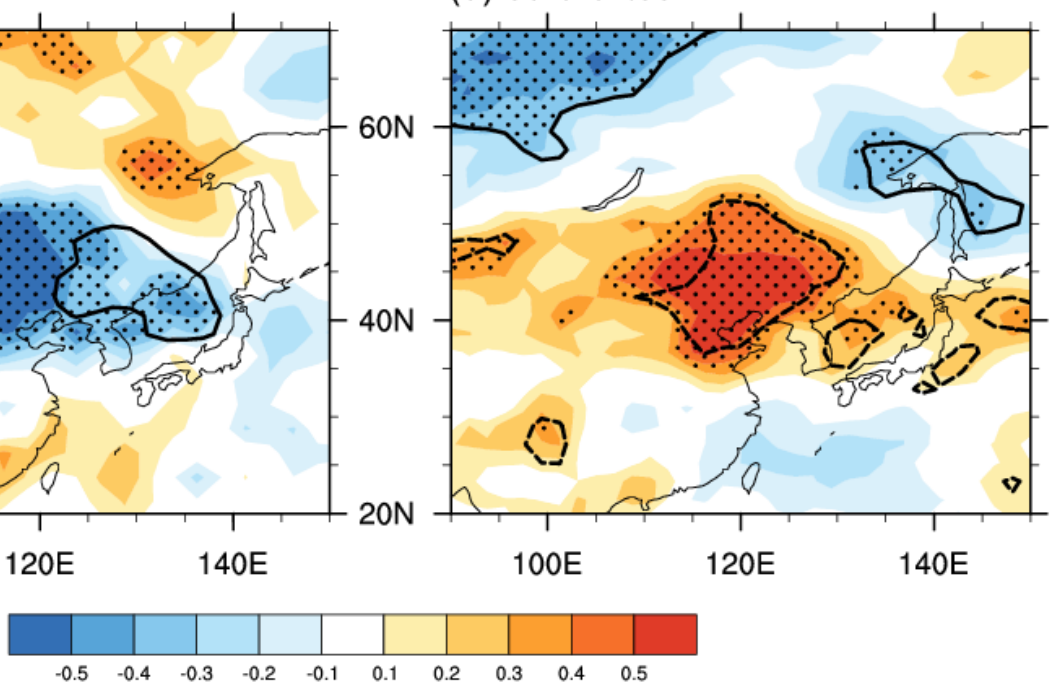

Figure S6. The correlation coefficients between the JJA mean OWI and (a) v wind at $10 \mathrm{~m}$ (shading), surface wind (arrow), (b) relative humidity near the surface (shading), boundary layer height (contour, data range 1979-2014), (c) precipitation (shading), downward UV radiation at the surface (contour, data range 1979-2014), (d) downward solar radiation at the surface (shading), the total cloud cover (contour) from 1979 to 2017. The black dots indicate that the CC with temperature was above the $95 \%$ confidence level. The contours plotted in panel (b-d) exceeded the $95 \%$ confidence level. The data used here are NCEP/NCAR datasets. 

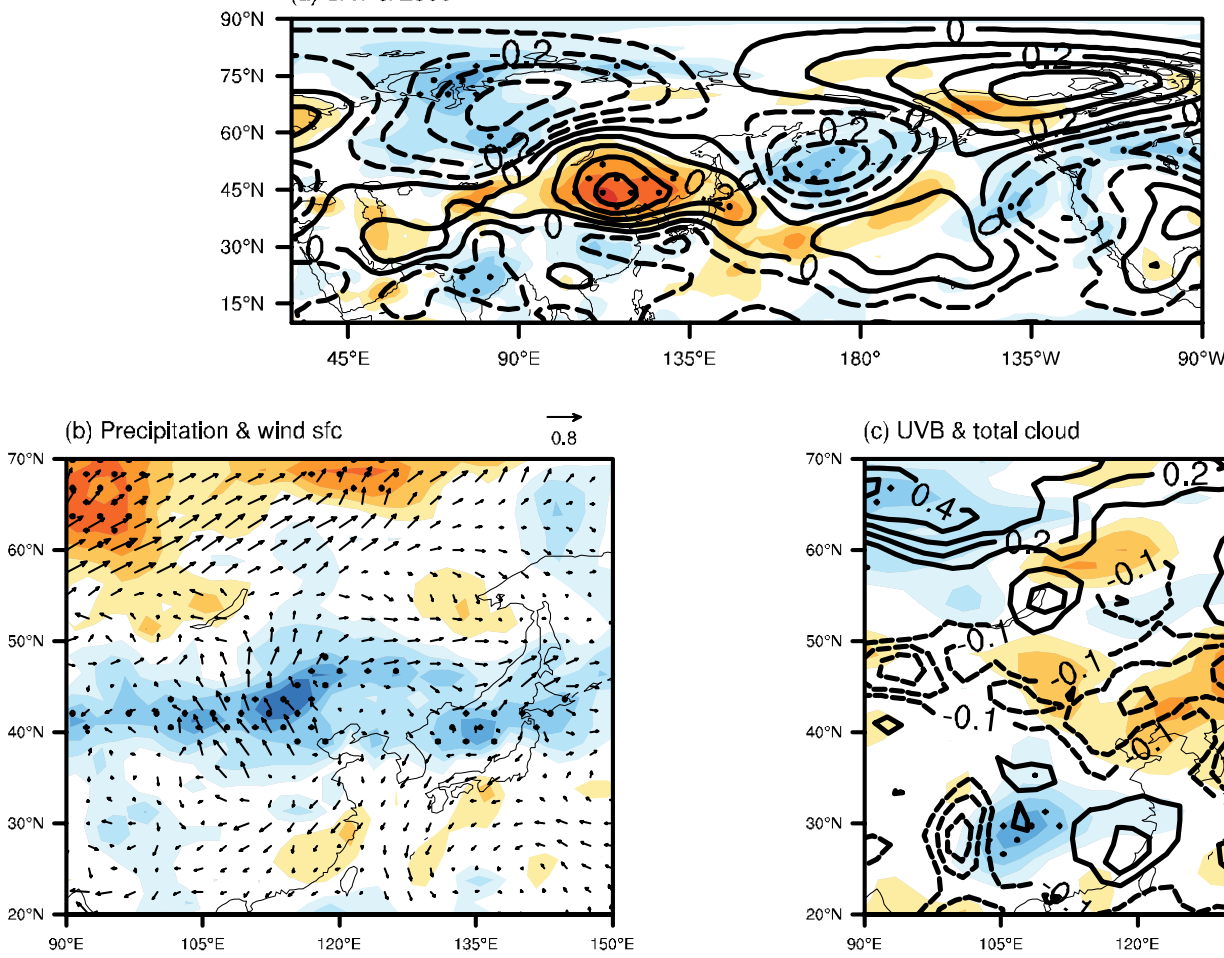

(c) UVB \& total cloud
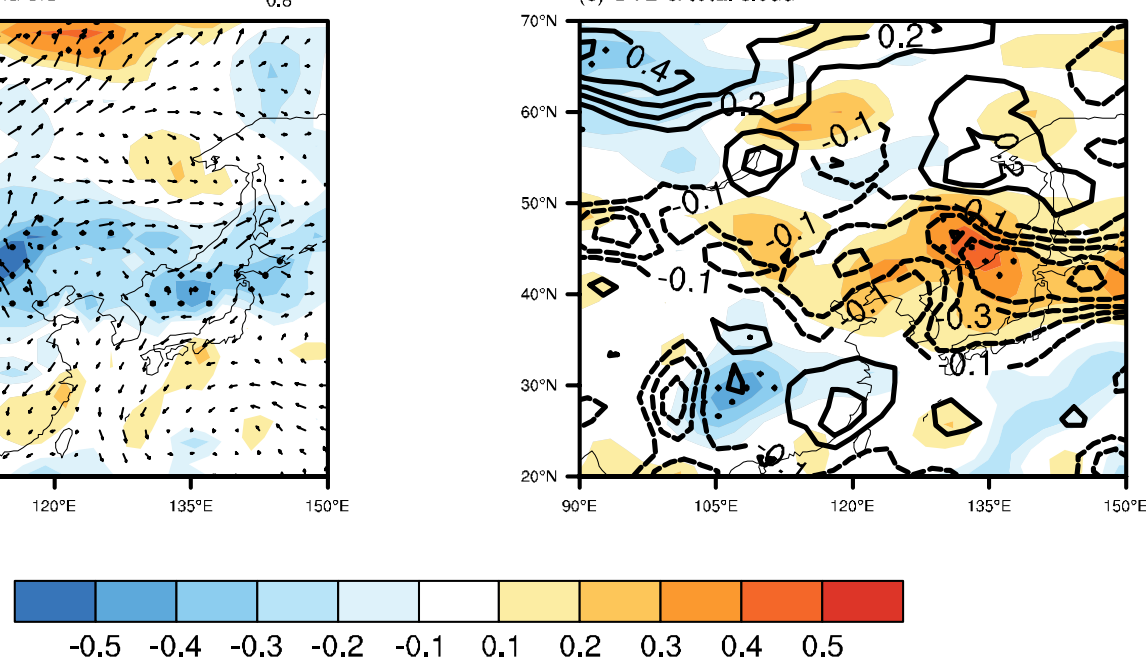

Figure S7. The correlation coefficients between the May SI index and (a) surface air temperature (shading), geopotential height at $500 \mathrm{hPa}$ (contour) from 1979 to 2017. (b) and precipitation (shading), surface wind (arrow), (c) downward UV radiation at the surface (shading, 1979-2014) and total cloud cover (contour) from 1979 to 2017. The black dots indicate that the CC with surface air temperature (a), precipitation (b) and downward UV radiation (c) was above the $95 \%$ confidence level. The data used here are NCEP/NCAR datasets. 